Darko Ilin

Univerzitet u Beogradu

Filološki fakultet

Srbija

darko.ilin@yandex.com
DOI: https://doi.org/10.18485/slovenika.2019.5.1.3

UDK: 821.163.41.09-1 Ристовић A.

Naučni članak

\title{
Radost ponovo nađene dvojine - interkulturni aspekti zbirke poezije Život na razglednici Ane Ristović
}

Sažetak

Cilj ovog rada je da pokaže na koji se način pesničko Ja u zbirci poezije Život na razglednici Ane Ristović etablira unutar druge kulture, te da se time ukaže na interkulturne aspekte ove zbirke. Osim pesama, na obodima zbirke nalaze se dva eseja, koja za temu imaju putovanje i upoznavanje drugih kultura, što doprinosi ne samo žanrovskoj kompleksnosti zbirke nego i podržava tezu da je važno istražiti interkulturne elemente zbirke. Središnja tema rada su pesme u kojima autorka tematizuje Sloveniju, te život i iskustvo navikavanja na novu sredinu jedne migrantkinje koja je napustila tadašnju Jugoslaviju. Ljubavna tematika kojom je prožeta zbirka predstavlja jedno od njenih tematskih čvorišta kojim je oslikano spajanje sa osobom koja predstavlja kulturno Drugo. Važan element istraživanja predstavljaju i načini interkulturne komunikacije, kao i strategije prevazilaženja kulturnih granica. U radu će biti analizirane određene pesme u kojima lirski subjekat sučeljava elemente kulture u kojoj je nekada živeo sa onom u kojoj trenutno živi i koja mu je strana. Preciznije, predmet analize biće aspekti slovenačke kulture koji su poetski preoblikovani u zbirci Život na razglednici, te će kroz analizu biti moguće doći do zaključka o tome na koji način se pesničkom obradom prevazilaze kulturne granice i uspostavlja interkulturna komunikacija.

Ključne reči: interkulturalnost, Slovenija, putovanje, ljubavna poezija, intimno 
Kompleksna istorijska slika naših prostora, a pogotovo naše bivše državne zajednice, uslovila je zanimljiv razvoj dveju donekle sličnih, ali umnogome i različitih kultura - srpske i slovenačke, kao i njihovih međusobnih odnosa. Važno je obratiti pažnju na neke zanemarene aspekte interkulturalnosti $u$ vezi sa slovenačkom i srpskom književnošću, a zbog same bliskosti, kako geografske tako i kulturološke, ovih dvaju naroda. Takođe, značajno bi bilo predstaviti interkulturne aspekte na primeru jedne medijatorske figure, savremene srpske pesnikinje Ane Ristović, u čijoj se poeziji mogu pronaći primeri za to na koji se način pesničko Ja etablira unutar druge - $u$ ovom slučaju slovenačke - kulture.

Kosmopolitski karakter postmodernog doba, uslovljen promenama na globalnom planu, postavlja pojedinca u jedan paradoksalan položaj, onaj u kojem mu se svet čini kao sasvim otvoreno mesto, $\mathrm{u}$ kojem su skoro sva egzogena iskustva užasno blizu, dok mu se istovremeno time umanjuje značaj tih iskustava, upravo zbog toga što postoji iluzija čovekove mogućnosti da bez mnogo truda interaguje sa Drugošću. Položaj savremenog subjekta tesno je vezan uz globalističke nazore i mogućnosti koje pružaju internet i drugi masovni mediji, te mu ne ostaje poznato samo ono što predstavlja njegovu sadašnjost, već pred sobom ima mogućnost da, zahvaljujući etnografskim praksama, ima uvid u različite običaje, kulture i načine življenja. Međutim, upravo takva mogućnost sveobuhvatnog uvida u različitost pospešuje i istovremeno problematizuje interkulturni položaj savremenog pojedinca, a zbog toga što se mogućnost uvida $\mathrm{u}$ druge kulture ostvaruje mahom kroz komercijalni i konzumeristički aspekt, dok se prenebregava onaj kritički. Upravo na takav način interkulturna komunikacija ostaje lišena svoje konačne suštine, a to je upoznavanje, poštovanje i razumevanje Drugoga.

Uloga književnosti u uspostavljanju i produbljivanju interkulturnih veza veoma je važna, te se, kako navodi Meta Grosman, svako sretanje čitalaca sa umetničkim tekstovima koji dolaze iz stranih kultura danas označava kao čitanje u interkulturnom položaju, jer pri čitaočevom susretu s tekstom iz druge kulture istovremeno dolazi i do susreta između čitaočeve izvorne kulture i kulture iz koje tekst dolazi. Pored neposrednog kontakta s drugim kulturama, i na ovakav posredan način bivaju istaknute i najvidljivije sličnosti, ali najčešće i razlike između tih kultura. Međutim, istovremeno sa započinjanjem tog sukoba počinje da se gradi interkulturna svest, koja je jedna od ključnih odlika savremenog čoveka i koja za cilj ima podrobno razumevanje bilo čega što je drugačije, kao i toleranciju prema drugosti (Grosman 2004, 43). 
Upravo tolerancija prema drugosti ima veoma važnu ulogu u kultura koje se mogu odrediti kao postjugoslovenske. Zaista, kompleksnost situacije na prostorima nekadašnje državne zajednice određena je jednim sveobuhvatnim procesom otuđivanja bliskoga, koje je bivalo sistematski sprovođeno kroz medije i politiku, ali i kroz jedan tok književnosti i kulture, tokom poslednje decenije dvadesetog stoleća. Generacije autora koji dolaze kasnije baviće se, između ostalog, ponovnim približavanjem onoga što je nekada bilo blisko, što se može odrediti i kao postjugoslovenska tendencija, koja se može primetiti i u zbirci Ane Ristović - Život na razglednici. Načini na koje se premošćuju kulturne, političke, jezičke i mnoge druge razlike među državama-naslednicama Jugoslavije, te interkulturni položaj u kojem se lirski subjekt ove zbirke nalazi, biće predmet ove analize.

Ovaj rad se fokusira na način na koji su te interkulturne veze predstavljene unutar samog poetskog teksta. Zbog toga je izbor Ane Ristović kao interkulturnog posrednika veoma povoljan. Naime, Ana Ristović je svoje formalno obrazovanje stekla u tadašnjoj SR Jugoslaviji i nakon toga se, krajem devedesetih godina prošloga veka, preselila u Sloveniju. U tom periodu usavršila je slovenački jezik i od tada deluje kao najvažniji savremeni prevodilac sa slovenačkog jezika - do sada je prevela oko 20 značajnih proznih i poetskih dela. Takva pozicija autora koji se nalazi na međi i koji predstavlja (inter) kulturnog medijatora između slovenačke i srpske kulture zahvalna je za analizu upravo iz tog razloga što pesnikinja svojim profesionalnim angažovanjem predstavlja proces interkulturnog dijaloga na javnom planu, dok se u njenoj poeziji očituje način na koji se takav dijalog uspostavlja na privatnom i intimnom nivou.

Pre dela koje predstavlja središte ovoga rada, u periodu između 1994. i 2003. godine, autorka je objavila tri zbirke poezije. Četvrta zbirka poezije Ane Ristović, Život na razglednici iz 2003. godine, unekoliko se razlikuje od njenih pređašnjih zbirki jer je to - prema određenju Bojane Stojanović-Pantović - „svojevrsni međužanrovski projekat" (Stojanović-Pantović 2014, 15), a zbog toga što je lirsko središte ove zbirke okruženo dvama tekstovima esejističke provenijencije. Tekst Air mail (sever) - Strinbergove olovke, kojim se zbirka otvara, predstavlja putopisni esej iz Švedske. Interkulturni aspekt zbirke istaknut je na samom početku eseja, referirajući na Crnjanskog i njegove zapise o putovanjima. Naime, imajući u vidu da se poetički koncept sumatraizma zasniva na povezivanju najudaljenijih, ali ipak po nečemu srodnih mesta i stvari i na ukrštanju takvih veza 
(Tatarenko 2013, 307), autorka na taj način nastavlja liniju svojevrsnog kosmopolitizma, koju predstavlja i Crnjanski. Takođe, uspostavljanje intertekstualnih veza unutar spisa putopisnog karaktera veoma je znakovito za tumačenje ideoloških i poetičkih aspekata samog dela. Naime, imajući u vidu da putopis uvek kreira sliku o Drugom, imagološko sagledavanje intertekstualnosti može navesti na pojam kulturnih granica, ,jer intertekstualnost nas upućuje na prelaske granica samog teksta dok putopis sa intertekstualnim aspektima jasno upućuje na otvorenost prema Drugom i prevazilaženje ili mogućnost prevazilaženja granica jedne kulture, kulture putopisca prema kulturi Drugog” (Sekulić 2017, 94). Na taj način ovaj putopis postaje teren za razumevanje interkulturnog položaja savremenog subjekta koji nastoji da prevaziđe granice nacija, ali i stereotipa o kulturama, koji su možda i čvršći od fizičkih granica.

Međutim, pravi kontekst za razumevanje koncepta putovanja, a samim tim i interkulturalnosti, nalazi se u zavšnom eseju, po kojem i sama zbirka nosi naziv - Život na razglednici. Naime, autorka u tom eseju, promišljajući koncept putovanja, dolazi do zaključka da postoje dve vrste ljudi koji putuju, te da se ti ljudi dele na putnike sa Zapada i putnike sa Istoka; putnici sa Istoka retko putuju, i to uvek zbog nekog određenog cilja, bilo da je to romantično putovanje ili zbog honorara koji će primiti, dok putnici sa Zapada putuju kako bi nesputano upoznavali druge kulture, time izgrađujući sebe kao savremenu individuu, koja je otelovljenje izreke „Što više putuješ, to više vrediš". Međutim, i sam koncept razglednice se u ovom eseju dekonstruiše tako što se sagledava kao simulakrum koji bi trebalo da predstavlja verodostojnu sliku mesta ili lokaliteta sa kojeg se putnik javlja. Autorka problematizuje upravo način prikazivanja tih virtuelnih i umetnih uspomena, jer ta mesta u najvećem broju slučajeva ne izgledaju onako kako su predstavljena na razglednicama, pa se taj život sa razglednica zapravo nikada i nije dogodio.

U šestom segmentu eseja nalazi se, poetski intoniran, uporedni pregled putnika sa Istoka i sa Zapada. Može se zaključiti da je autorka kritički nastrojena prema putnicima sa Zapada: „Ponekad pomislim da putnik sa Zapada zapravo ne putuje na Istok da bi upoznao 'drugost' kao takvu (iako se najčešće tim razlozima i vodi) već da bi, konformistički odgajan, našao Zapad na Istoku: svaki veći iskorak obično mu kida živce" (Ristović 2003, 85). Na ovom mestu se može istaći i polemički aspekt ovog eseja u vezi s kolonijalnom i zapadnocentričnom tradicijom, koja je zagledana u sebe čak i pri upoznavanju s drugim kulturama. Ovaj esej u sebi sadrži potencijal postko- 
lonijalističkog propitivanja upravo zbog toga što kritikuje diskurse moći i relativizuje uvrežene istine i činjenice, te predstavlja jedan pogled iskosa i decentriranje fokusa (Miladinov 2015, 161). Tema ovog eseja je i putopisni diskurs, gde se svakako uključuje i način na koji vidimo drugost, zbog čega se u njemu može primetiti i moćan impuls imagološke analize načina na koji putnici iz, tradicionalno posmatrano, suprot(stavlje)nih kultura vide drugost, a samim tim i način na koji se snalaze $u$ interkulturnom položaju.

Stručnjaci ističu da je narušavanje žanrovskih očekivanja zapravo neka vrsta programskog načela ove zbirke, jer se upravo izlaskom u drugost (bilo žanrovsku, bilo kulturnu) pesnikinja suočava sa sobom i vlastitim granicama (Stojanović-Pantović, 2014, 15). Upravo u takvom odnosu prema tvrdim granicama kako žanra tako i nacionalnog identiteta očituje se ideološki stav prema monolitnim strukturama, koje se smatraju umetnim, te se nastoji da one budu prevaziđene. Međutim, bilo bi suviše usko posmatrati ovakav postupak kao čisto postmodernističko poigravanje s tekstom, zbog toga što se u ovoj zbirci otkriva novi način iskrenosti i prevazilaženja konstrukta, ali ne na intelektualistički i razigrani način, na koji to čini postmoderna književnost, već kroz duboko intiman i pre svega kritički nastrojen odnos prema svetu.

U središtu ove žanrovski heterogene zbirke nalazi se lirsko središte naslovljeno sa Sobne muve (-severozapad), što se može interpretirati kao simboličko upućivanje na nemogućnost odlaska ili na stanje bez želje za izlaskom iz ograničenog prostora (sobe), odnosno - za putovanjem. Međutim, takav naslov biće na jedan način izneveren, zbog toga što se u zbirci nalaze pesme koje tematizuju prevazilaženje takvog ograničenja. Pomenuti izlazak u drugost najizrazitiji je u četirma pesmama koje tematizuju navikavanje na područje u kojem se lirski subjekt oseća stranim, zbog toga što je stran datoj kulturi, ali je istovremeno i svoj, budući da je razlog putovanja lirskog subjekta - ljubav. Naime, na samom početku zbirke, jedna za drugom nalaze se pesme Jezik, moj jež, Tolari i dinari i Smrznute sarmice, i one su povezane zajedničkim tematskim obeležjima - statusom pojedinca u međukulturnom položaju, upravo između srpske kulture kao matične i slovenačke kulture, $u$ kojoj se lirski subjekt nalazi.

Pesma s naslovom Jezik, moj jež tematizuje jedan od najznačajnijih elemenata iskustva odlaska u drugost, a posebno migrantskog iskustva. Naime, samim odlaskom u prostor koji je označen jezikom koji je subjektu stran, taj se subjekt nalazi u situaciji kada mora da 
prevaziđe svoje epistemološke granice i da kroči ne samo na teritoriju koja je geografski različita od njegove matične, već na kojoj jezik, a samim tim i obrasci mišljenja, funkcionišu na drukčiji način. U ovom konkretnom primeru je takva situacija metaforički predstavljena zvukom (govorom) kao realizacijom jezika, te se ovde problematizuje način na koji se migrant oseća u državi čiji mu je jezik stran i koji će zauvek govoriti stranim naglaskom, ma koliko dobro taj jezik naučio:

Ljubljanski taksisti se klade

da sam iz Ukrajine.

Na moje „Dobar dan“, požele mi dobru noć moj slovenački miriše na jug ili istok, siguran užitak.

(Ristović 2003, 30)

Pripadnici dominantne, slovenačke kulture percipiraju na svom tlu lirskog subjekta kao stranca na osnovu jezika, na osnovu načina na koji zvuči, što ih podseća na jug ili istok, samim tim - na drugost. Drukčije rečeno, jezik kao način na koji individua sebe izražava u svetu predstavlja se ovde kao barijera, kao oznaka da lirski subjekt ne pripada kulturi u kojoj se trenutno nalazi. Međutim, važno je naglasiti istančanost izbora slika koje izgrađuju ovu lirsku situaciju - kao merodavne sudije izabrani su upravo taksisti, koji ovde predstavljaju „prvu liniju odbrane” nacionalne kulture, odnosno, prvo što će novopridošla susresti po dolasku u Ljubljanu. S druge strane, oni bi morali biti neka vrsta kulturnog medijatora upravo zbog svog interkulturnog položaja, te najbolje mogu oceniti odakle neko dolazi na osnovu mnogih prethodnih iskustava sa strancima. Uz to, njihovo klađenje oko identiteta lirskog subjekta može se tumačiti kao nonšalantna objektifikacija s kojom se došljak susreće, gde njegovo poreklo postaje jedan kuriozitet kojim pripadnici dominantne kulture prekraćuju svoje vreme, prenebregavajući time činjenicu da sebe iznova etabliraju kao centar, dok istovremeno utvrđuju podređenost figure došljaka.

Međutim, jezička situacija u ovoj pesmi predstavljena je unekoliko kompleksnije u narednim stihovima:

Beogradski misle

da dolazim iz užičkih krajeva:

otežem, tvrde, kao Morava pred sušu. 
A oni oko autobuske stanice na koju stižem umorna od puta kažu da mi Ć nije kao njihovo meko, mora da sam Slovenka (Ristović 2003, 30)

U ovim stihovima implicira se da lirski subjekt ima status pridošlice, a samim tim i da se nalazi $u$ vrednosno nižoj poziciji u odnosu na dominantnu kulturu i u svojoj sopstvenoj državi. Naime, ovakva situacija može se tumačiti kao opšta obeskorenjenost lirskog subjekta, što s jedne strane i jeste jedna od tema ove zbirke, imajući $\mathrm{u}$ vidu da se motiv putovanja često može povezati s motivom obeskorenjenosti ili barem pokušaja da se ponovo uspostavi ravnoteža između sebe i Drugoga. Međutim, ovo se takođe može tumačiti i kao tipična situacija liminalne pozicije subjekta, one koja se nalazi između dve kulture - ne više u jednoj, ali ne još u drugoj.

Taksisti se, takođe, između ostalog pitaju „i čija su dva glasna A iz imena/ oko mojih ruku i vrata, umesto omče" (Ristović 2003, 31). Na ovom mestu postavljeno je važno pitanje imena, a samim tim i identiteta, koji je ovde predstavljen kao teret, kao sredstvo koje ograničava kretanje i život sâm. Kroz ovakvo poetsko posredovanje jastva predočava se savremeno stanje subjektiviteta, koje je usled mnoštva različitih misaonih paradigmi u dvadesetom stoleću dekonstruisano, te se u centar postavlja štetnost nametnutog tradicionalnog poimanja identiteta. „Upravo zbog toga što su identiteti konstruirani unutar, a ne izvan diskurza, trebamo ih razumjeti kao proizvode specifičnih strategija iskazivanja u specifičnim historijskim i institucionalnim mjestima u kojima se koriste specifične diskurzivne formacije i prakse" (Hall 2001, 219). Na ovom mestu je važno istaći upravo taj sukob između esencijalističkog poimanja identiteta kao tradicionalnog i monolitnog jedinstva i poimanja identiteta kao fluidnog konstrukta, koji neprestano nastaje u diskursu, ostaje zauvek nefiksiran i spreman za interkulturnu komunikaciju.

U narednom segmentu pesme, lirski subjekt se fokusira na razlog svog interkultulnog položaja - na ljubav. O stihovima „Kao zaverenici, sastajemo se/ u bescarinskoj zoni, na pola puta" (Ristović 2003, 31) promišlja hrvatska pesnikinja Darija Žilić: „Ta 'multikulturalna' ljubav kao da se hrani upravo prelaženjem granica; nakon toliko godina neputovanja, udaljenost između dva grada u različitim državama, postaje privlačna, a putovanje nimalo zamorno" (Žilić 2004, 122). Na ovom mestu se D. Žilić osvrće na realije koje ona vidi kao 
podlogu ove pesme, imajući u vidu da poznaje samu autorku. Naime, ona se osvrće na godine neputovanja, na šta i sama autorka aludira u svojim esejima, te se ističe da su ova dva grada - Ljubljana i Beograd - dva grada u sada različitim državama, između kojih postoje granice, ali da se njihovo prelaženje iznova i iznova događa uzrokovano ljubavlju.

Upravo ova multikulturalna ljubav istaknuta je na kraju pesme i kao multijezička ljubav:

Osuđeni jedno na drugo, gramatičke revolucije preživljavamo ćutke:

ja radost ponovo nađene dvojine, on, strah od crnog imperfekta

(Ristović 2003, 31)

Naime, sa stanovišta konotacije, u pesmi čitalac može primetiti razlike između slovenačkog i srpskog jezika, odnosno - postojanje dvojine kao gramatičke kategorije broja, koja u srpskom jeziku više ne postoji, i imperfekta, glagolskog oblika koji se nije održao u savremenom slovenačkom jeziku. Međutim, važno je osvrnuti se na značenja koja se pomenom jezičkih kategorija ostvaruju. Dvojina je kao morfološka kategorija zavređivala pažnju brojnih proučavalaca jezika, koji su o njenoj praktičnoj upotrebnosti i semantičkoj opravdanosti imali prilično različita mišljenja. Tako, od Tenijerovog stava da je dvojina znak niskog civilizacijskog stupnja, preko Humboltovog stava da je pojam dvojnosti duboko ukorenjen u čovekovom poimanju sveta, do stavova koje je, pozivajući se na Humbolta i Jakobsona, izneo Rado Lenček - da poetska funkcija dvojine predstavlja semantički značajno sredstvo u ljubavnoj poeziji, budući da osim gramatičke informacije implicira i savezništvo i posebno intiman odnos dva pojedinca (Derganc 2006, 67-68). Dvojina ne može biti upotrebljena umesto jednine ili množine (Vlahović 1990, 313), te je ona ne samo jedna od opcija, već i jedina moguća opcija kojom bi se iskazala zajednica dvaju entiteta. Zbog toga lirski subjekt vidi ponovo nađenu dvojinu kao savršen način da u jezik prenese sijaset različitih značenja - od jezičkog, kulturnog i fizičkog spajanja dveju jedinki, preko postojanja jezičke, a samim tim i epistemološke kategorije $u$ kojoj su lirski subjekt i njen partner jedina dva entiteta, do evociranja platonističke figure androgina i narativa o ponovnom nalaženju izgubljene polovine nekadašnjega dvojca. Uz to, treba obratiti posebnu pažnju na predstavu ljubavi kao gramatičkih revolucija, odnosno - na prevazilaženje jezičke barijere u ljubavi iz- 
među lirskog subjekta i njenog partnera koji govori drugim jezikom i dolazi iz drugačije kulture. Jedina stvar koja pomaže pri izlasku iz interkulturalnog limba jeste zapravo ljubav, što je, pored teme putovanja, središnja tema ove zbirke.

U drugoj pesmi, Tolari i dinari, tematika pojedinca u migraciji biva produbljena: „Tolari i dinari se mešaju u mom džepu:/ zenit i pomračenje sunca/ u istom času, na obe strane neba” (Ristović 2003, 32). Tolari kao slovenačka valuta u vremenu kada je zbirka napisana i valuta domovine lirskog subjekta mešaju se u njenom džepu, što se može tumačiti kao potpuna afirmacija jednog pojedinca kao interkulturnog subjekta. Samim tim, afirmiše se i stav da unutar osobe $u$ liminalnom kulturnom položaju ne može postojati samo jedna valuta, te jedan identitet, već da je reč o totalitetu različitosti i suprotnosti, čime se podržava shvatanje o identitetu kao homogenom konstruktu, te afirmiše jedan kompleksniji pogled, barem sa stanovišta interkulturalnosti. Uz to se i zajednica lirskog subjekta sa njegovim slovenačkim partnerom definiše kao „najmanja država na svetu/ sa revolucionarnim programom/ uvek u nacrtu" (Ristović $2003,33)$, što ponovo upućuje na erotsku tematiku zbirke i na ljubav kao jedino moguće ishodište, te tako upravo na način da se prevaziđu fizičke granice i istakne intimna i revolucionarna državotvornost koja počiva na ljubavi.

Treća pesma nosi naslov Smrznute sarmice, čime se upućuje na motiv udaljenosti od doma:

Preko tri granice,

kroz tri države

putuju na usijanim gumama

sa mnom, ka tebi

smrznute sarmice

(Ristović 2003, 34)

Naime, evociranjem poznate situacije slanja hrane od kuće evocira se situacija u kojoj se lirski subjekt nalazi daleko od kuće, a uz to se sarmice mogu shvatiti kako simbol nacionalnog indentiteta lirskog subjekta, te se priča o putovanju smrznutih sarmica može tumačiti i kao transgresija koncepta nacionalnog identiteta unutar lirskog subjekta. Upravo ova pesma simbolički upućuje na proces migracija, uključujući u sebe taj motiv, pri čemu se ima u vidu i to da je upravo kompleksni fenomen migracija simptom političnih razlika na globalnom planu, ali i u manjim, geografski ograničenim kontekstima. Stoga uočavanje i interpretacija takvih motiva doprinosi 
razumevanju društvenih odnosa koji ga karakterišu (Stojić Mitrović 2017, 26). Migrantska situacija o kojoj je reč u ovoj intimističkoj lirici zapravo je bliska konceptu transnacionalne književnosti, koju pišu autori i autorke koji su izmešteni; međutim, od tog se koncepta ova zbirka razlikuje po tome što autorka piše na svom maternjem jeziku, na kojem na najbolji način može izraziti sudar svoga jezika i kulture sa onim koji je sada okružuje.

Na semantički povlašćenom mestu, odnosno - na samom kraju lirskog središta ove zbirke, nalazi se nenaslovljena pesma, koja ponovo, nakon niza pesama koje tematizuju stvaranje, pesničku tradiciju i, svakako, ljubav, progovara o lirskom subjektu iz Srbije i njenom partneru iz Slovenije kontrastiranjem nekih nacionalnih obeležja jedne i druge države, tvoreći na taj način među njima jednu intimnu interkulturnu zajednicu:

Meni rimski bunar

u trbuhu

Tebi petsto turskih godina

pred vratima

Tebi davno priznata dvojina

Meni dvojina sačuvana

od svakog vuka

(Ristović 2003, 71)

U ovoj pesmi, kojom se okončava lirsko središte zbirke Život na razglednici, lirski subjekt ulazi u nacionalne imaginarijume obeju država, Srbije i Slovenije, pronalazeći u njima mesto preseka lirskog subjekta i njenog partnera. Referišuči najpre na rimski bunar kao specifičnost beogradskog Kalemegdana, otkriva se mnoštvo mogućih značenja, prvo zbog toga što je taj bunar izgrađen u 18. veku, a tek se kasnije u njega slilo obilje simbolike koja ga je povezala $\mathrm{s}$ rimskim vremenima. Na taj način, lirski subjekt možda referiše na stalnu i svevremenu mogućnost prevrednovanja činjenica, tako što im se pripisuje drugačiji semantički potencijal, a samim tim, ponovo, i na fluidnost identiteta kao odliku savremenog subjekta. S druge strane, imajući u vidu da i Beograd i Ljubljanu povezuje rimsko nasleđe, kao i, u Srbiji veoma intenzivan, a u Sloveniji manji, ali svakako značajan, kontakt sa Osmanskom imperijom, koja je ovim prostorima vladala petsto godina, ovaj segment pesme poziva se i na zajedničko kulturno i civilizacijsko nasleđe ovih dvaju naroda. Lirski segment ove zbirke završava se pomenom dvojine, 
koja obeležava ovaj korpus pesama. Upravo pozivajući se na skupno sveslovensko nasleđe koje prožima ove dve kulture, te na jezik koji je jednom davno bio zajednički i imao dvojinu, reartikuliše se ideja ponovo pronađene dvojine, koja je nekada davno postojala. Pomen vuka koji predstavlja opasnost po dvojinu, s jedne strane, najintenzivnije inkorporira elemente tradicije, jer može predstavljati mitološku figuru vuka kao svete životinje Slovena, dok se s druge strane može shvatiti i kao referisanje na jezikotvorni proces u kome je srpski jezik izgubio dvojinu kao morfološku kategoriju u punom intenzitetu. Pominjanje ovakvih kulturno specifičnih momenata aktivira jedan paradoksalni proces spajanja i razdvajanja, istosti u različitosti, osobenosti u zajedništvu, što se zapravo može razumeti kao suštastvena osobina ljubavnog odnosa lirskog subjekta prema voljenom, ali i kao šira i sveobuhvatnija humanistička poruka o optimalnom međusobnom odnosu ljudi uopšte.

Korpus pesama koje tematizuju odnos migrantkinje iz Srbije sa slovenačkom kulturom u kojoj se našla veoma je važan za sagledavanje interkulturnih aspekata ove zbirke, te se u tumačenju svakako mora poći od empirijske stvarnosti, pošto ova zbirka intimističke lirike umnogome referiše na stvarnu Anu Ristović i njen život. Međutim, suptilnost kojom je predstavljen način aklimatizacije sopstvenog identiteta na život $u$ drugoj državi, život $u$ drugom jeziku, drugoj kulturi i, uostalom, jednoj multikulturnoj ljubavi izdižu se kao opšti i veoma umetnički uspeli aspekti ove zbirke. Ipak, otvara se pitanje kako lirski subjekt u ovoj zbirci, koji se nalazi u interkulturnom položaju, te odbacuje koncept čvrstog identiteta, posmatra sebe u odnosu na svoju tranziciju. Da li se odbacivanjem tog koncepta lirski subjekt ove zbirke približava onom kosmopolitskom sumatraisti na kojega na samom početku zbirke referiše? Odgovor je najverovatnije mnogo komplikovaniji od toga. Upravo na tom mestu neodređenosti nalazi se radost ponovo nađene dvojine. I to radost dvojine ne samo kao morfološke kategorije koju je slovenački jezik sačuvao, već - kako kaže Ana Ristović - radost života u dvojini, u najmanjoj državi na svetu, uz osuđenost na zajedničko preživljavanje gramatičkih i još ponekih revolucija. 
Literatura

Derganc, Aleksandra. 2006. Nekatere značilnosti dvojine v slovenščini. Slavistična revija 54 (1): 57-71.

Grosman, Meta. 2004. Književnost v medkuturnem položaju. Ljubljana: Znanstveni inštitut Filozofske fakultete.

Hall, Stewart. 2001. Kome treba „identitet“? Reč : časopis za književnost $i$ kulturu 64 (10): 215-233.

Miladinov, Branislava. 2015. Postkolonijalna teorija: pregled problema. Anali Filološkog fakulteta 27 (2): 159-197.

Ristović, Ana. 2003. Život na razglednici. Beograd: Plato.

Sekulić, Mirjana M. 2017. Intertekstualnost putopisa u funkciji otkrivanja drugog. Lipar XVIII: 87-96.

Stojanović-Pantović, Bojana. 2014. Lirski agon. Disovo proleće 45: 15.

Stojić Mitrović, Marta. 2017. Neki izazovi terenskog proučavanja neautorizovanih migracija $u$ etnologiji $i$ antropologiji: multilokacijska etnografska istraživanja. Slovenika: časopis za kulturu, nauku i obrazovanje 3: 23-34.

Tatarenko, Ala. 2013. „Poezija kao ispovest nove vere: o sumatraizmu Miloša Crnjanskog“. U Miloš Crnjanski: poezija i komentari, ur. Dragan Hamović, 292-309. Beograd: Institut za književnost i umetnost.

Vlahović, Maja. 1990. Modeli transpozicije dvojine (na primeru prevođenja sa slovenačkog na srpski). Naučni sastanak slavista $u$ Vukove dane $\mathrm{XX} / 2:$ 311-315.

Žilić, Darija. 2004. Zanesenost umanjivanjem : prikaz knjige Život na razglednici Ane Ristović. Polja 429: 121-123.

Darko Ilin

Univerza v Beogradu

Filološka fakulteta

Srbija

RADOST PONOVNO NAJDENE DVOJINE - MEDKULTURNI VIDIKI ZBIRKE POEZIJE ŽIVLJENJE NA RAZGLEDNICI ANE RISTOVIĆ

Cilj tega članka je, da pokaže, kako se pesniški Jaz v zbirki poezije Življenje na razglednici Ane Ristović vzpostavlja znotraj druge kulture, ter s tem opozori na medkulturne vidike zbirke. Poleg pesmi se na robovih zbirke nahajata dva eseja, ki obravnavata potovanje in spoznavanje drugih kultur, kar prispeva ne samo k žanrski komple- 
ksnosti zbirke, ampak tudi $\mathrm{k}$ temu, da je pomembno raziskati medkulturne elemente zbirke. Osrednja tema članka so pesmi, v katerih avtorica tematizira Slovenijo in življenje ter privajanje migrantke, ki je zapustila tedanjo SR Jugoslavijo. Ljubezenska motivika, s katero je zbirka prepredena, predstavlja eno njenih tematskih središč, $s$ čimer je upodobljeno združevanje z osebo, ki je kulturološki Drugi. Pomemben element raziskave predstavljajo tudi načini interkulturne komunikacije ter strategije preseganja kulturnih meja. Predmet analize so pesmi, v katerih lirski subjekt sooča elemente kulture, znotraj katere je živel nekoč, s tisto, v kateri trenutno živi in mu je tuja. Pomensko središče torej predstavljajo aspekti slovenske kulture, ki so na pesniški način preoblikovani v zbirki Življenje na razglednici, z analizo pa bo mogoče skleniti, na kakšen način se $s$ pesniško predelavo presega kulturne meje in odpira medkulturno komunikacijo.

Ključne besede: medkulturnost, Slovenija, potovanje, ljubezenska poezija, intimno

Darko Ilin

University of Belgrade

Faculty of Philology

Serbia

JOY OF THE REGAINED DUAL - INTERCULTURAL ASPECTS OF THE COLLECTION OF POEMS LIFE ON A POSTCARD BY ANA RISTOVIĆ

The aim of this paper is to show the way in which the lyrical subject of Život na razglednici, a collection of poems by Ana Ristović, is established in another culture and to highlight the intercultural aspects of this collection. Apart from poems, the collection includes two essays on travelling and exploring other cultures, which not only adds to the genre complexity of the book but it also encourages the idea that it is important to explore its intercultural aspects. The central topic of the paper are the poems in which the author dwells upon Slovenia and the life and accommodation of an immigrant who left former SR Yugoslavia. The topic of love imbues the entire collection and is one of the main topics that helps describe the unity with a person representing the cultural Otherness. An important element of this research focuses on the ways of intercultural communication and the strategies of transcending cultural boundaries. The poems in which the lyrical subject confronts the elements of her maternal culture with the one in which she is living now and which is foreign to her will be analyzed. In other words, the 
aspects of Slovenian culture that have been transformed through poetry will be analyzed, thereby enabling us to discover the way in which poetic transposition paves the way towards transcending cultural boundaries and establishing intercultural communication.

Keywords: intercultural, Slovenia, travelling, love poems, intimate 